\title{
Vaginal Delivery versus Elective Caesarean Section for Breech Presentation - Experience in Institute of Child and Mother Health (ICMH)
}

\author{
Mahe Jabeen *1, Sabiha Shimul ${ }^{2}$, Ummay Salma ${ }^{3}$, Jebunnesa ${ }^{4}$
}

\begin{abstract}
Introduction: Compared with a fetus with cephalic presentation, a breech fetus faces increased risk during labour and delivery of asphyxia from cord compression and of traumatic injury during delivery of the shoulders and head. Caesarean section avoids most of this risk. The purpose of this study was to evaluate the feasibility of vaginal delivery of uncomplicated singleton breech presentation by evaluating early neonatal morbidity and mortality as well as maternal morbidity following vaginal and caesarean delivery for breech presentation. Materials and Methods: This is a cross sectional comparative study.104 women with singleton breech presentation at term in labour were included consequetively in labour ward of Institute of Child and Mother Health (ICMH). Informed consent was taken from them. Neonatal and maternal outcome were recorded and statistical analysis was done using SPSS version 22. Results: APGAR at 5 min and Neonatal Intensive Care Unite (NICU) admission were not affected by mode of delivery. Long term neonatal outcome is similar in either mode of delivery. Maternal morbidity and duration of hospital stay is increased in caesarean births. Conclusion: Neonatal outcome did not depend on mode of delivery though maternal morbidity and cost of care is increased following Caesarean Section. Proper selection of cases and by improving skill \& confidence in new generation obstetrician, vaginal delivery of singleton fetuses in breech presentation at term remains a safe option that can be offered to a woman in a tertiary care centre.
\end{abstract}

Keywords: Vaginal delivery, Caesarian section, Breech presentation.

Number of Tables: 03; Number References: 15; Number of Correspondences: 01

*1. Corresponding Author: Dr. Mahe Jabeen

Associate Professor, Department of Obs \& Gynae

Institute of Child and Mother Health (ICMH), Matuail, Dhaka.

Email: rinkujabeen@gmail.com

2. Dr. Sabiha Shimul

Registrar, Department of Obs \& Gynae

US Bangla Medical College \& Hospital, Narayangonj.

3. Dr. Ummay Salma

Assistant Professor, Department of Obs \& Gynae

Kumudini Women's Medical College \& Hospital, Tangail.

4. Dr. Jebunnesa

Assistant Registrar, Lab Medicine

Institute of Child and Mother Health (ICMH), Matuail, Dhaka.

\section{Introduction}

Incidence of breech presentation is $3 \%$ to $4 \%$ in singleton pregnancies at term. Mode of delivery in breech presentation has long been a topic of debate. Many studies including the Term Breech Trial (TBT) ${ }^{1}$ have concluded that vaginal breech delivery at term is associated with increased perinatal morbidity and mortality ${ }^{1-3}$. Vaginal breech delivery has also been reported with an increased risk of fetal trauma ${ }^{1-3}$. The TBT by Hannah et al. ${ }^{1}$ published in 2000, made many obstetricians believe that neonatal risks associated with term breech births are much higher among planned vaginal deliveries and implied that Caesarean Section (CS) should be systematically planned for all such women. These consequently led American College of Obstetricians \& Gynaecologists (ACOG) to officially recommend in 2001 that CS should be performed in the case of a singleton breech at term. This recommendation led to a radical change in practice, with a CS rate as high as $86.9 \%$ in the United States in 2002 for breech presentations at term ${ }^{4}$. On the other hand, CS has risks; it is associated with more significant short- and long-term maternal morbidity, as well as a higher rate of complications during subsequent pregnancies than vaginal delivery $^{2}$. Contrary to prevailing practice French obstetricians continued to perform vaginal breech deliveries at term, with reassuring results. Various retrospective observational studies done in Europe and published in the last decade show planned vaginal delivery rates for term breech presentations to be as high as $54 \% 0^{5-9}$. It was concluded in 2000 that "there is insufficient current evidence to allow the systematic performance of a CS in the case of a breech presentation" ${ }^{10}$. Various studies made ACOG to modify the previous recommendations in July 2006 declaring that vaginal delivery of a breech presentation may be acceptable under specific circumstances $^{11}$. The 2006 Royal College of Obstetricians \& Gynecologists (RCOG) Green Top Guidelines on breech birth outlines the obstetrical community's responsibility to the individual parturient: "If a unit is unable to offer the choice of a planned vaginal breech birth, women who wish to choose this option should be referred to a unit where this option is available" ${ }^{12}$. Keeping the abo ve background in mind we conducted an observational prospective study without modifying obstetric practices to evaluate neonatal and maternaloutcome following both mode of delivery for breech presentation at term.

\section{Materials and Methods}

This cross sectional comparative study conducted over a period of six months at The Department of Obstetrics and Gynaecology of ICMH from January to June 2016. 
104 women who presented to emergency during this period with singleton live fetus in breech presentation and more than 34 weeks of gestation in labour were enrolled in the study. 104 women of singleton breech presentation in term pregnancy were done elective $\mathrm{c} / \mathrm{s}$ were included as a comparative group.

A thorough feto-maternal assessment including fetal wt. estimation, pelvic assessment and fetal heart rate was done. Women with associated absolute and relative obstetrical indication like contracted pelvis, placenta previa, IUGR, previous caesarean, fetal macrosomia, severe oligohydroamnios were prepared for caesarean while rest of the women, found to be fit for vaginal delivery, were counseled about the risks and benefits of vaginal and caesarean delivery and were planned accordingly after informed consent. Women willing for vaginal delivery were shifted to labor room and admission CTG was done to assess fetal well-being. Women for vaginal births were vigilantly monitored in labor room, partograph was maintained and at any time during labor if there is development of any indication for urgent delivery like cord prolapse, fetal distress, non-progress of labor CS was done after informed consent. Vaginal delivery was conducted by senior resident or senior post graduate in presence of pediatrician. Maternal and neonatal outcome in either mode of delivery was recorded. The variables in neonatal outcome included birth weight, APGAR score at $5 \mathrm{~min}$, admission and duration of stay in neonatal intensive care unit. Maternal outcome was studied in terms of postnatal complications like pain, Post-Partum Haemorrhage (PPH) \& duration of hospital stay. Statistical analysis of data was performedusing SPSS version 22.

\section{Results}

Total 208 women were enrolled in the study. Out of these 208 women, 30 came in advanced labor and delivered immediately and 53 were prepared for caesarean for associated obstetrical complications. Rest 207 (71.3\%) women who were in early labor were carefully assessed and explained about the risks and benefits of either mode of delivery and were planned according to the patient's choice. $170(82 \%)$ out of 207 gave consent for caesarean and only 37 women (18\%) were wiling for vaginal delivery. Hospital being a busy tertiary referral hospital, amidst heavy work load, at times due to unavailability of operation theatre, a large number of females consenting for caesarean delivered vaginally. Total $158(54.5 \%)$ delivered vaginally and $132(45.5 \%)$ had caesarean section. The demographic characteristics (Table I) of the women in both groups were comparable.

Table-I:Parity distribution.

\begin{tabular}{lcc}
\hline Parity & Vaginal delivery & Caesarean section \\
\hline Nullipara & $36(22.78 \%)$ & $82(62.12 \%)$ \\
1 & $28(17.72 \%)$ & $29(21.97 \%)$ \\
2 & $58(36.71 \%)$ & $21(15.91 \%)$ \\
3 & $25(15.82 \%)$ & $0(0.0 \%)$ \\
$\geq 4$ & $611(6.96 \%)$ & $0(0.0 \%)$ \\
\hline
\end{tabular}

On analyzing it is observed that variables like extension of operative wound, postpartum haemorrhage were comparable in both vaginal and caesarean delivery groups but postpartum pain and average hospital stay was less following vaginal delivery than CS (4.3 days in caesarean and 2.2 days in vaginal births). The average birth weight in either group was comparable (Caesarean $2.65 \mathrm{~kg}$ and vaginal 2.58 $\mathrm{kg}$ ). There was no intranatal death. There was one early neonatal death in vaginal delivery group and it was due to severe IUGR. Neonatal outcome following either mode of delivery was comparable $(\mathrm{P}=0.545)$.

As shown in Table II, APGAR score at 5 min was similar in both the groups which implies that mode of delivery $(\mathrm{P}=$ 0.492) does not influence neonatal outcome. Neonatal nursery (NICU) admission was $19 \%$ in vaginal group compared to $17.4 \%$ in caesarean group $(\mathrm{P}=0.426)$. Mean duration of NICU admission is 0.73 days in vaginal birth group and 1.02 days in caesarean delivery group $(\mathrm{P}=$ 0.359). Thus, NICU admission and stay was not related to mode of delivery but depends on overall status of mother and fetus.

Table-II:Neonatal outcome in the two groups.

\begin{tabular}{lccc}
\hline $\begin{array}{l}\text { Outcome } \\
\text { variable }\end{array}$ & $\begin{array}{c}\text { Vaginal delivery } \\
(\mathbf{n}=104)\end{array}$ & $\begin{array}{c}\text { Caesarean } \\
\text { deliver }(\mathbf{n}=104)\end{array}$ & $\begin{array}{c}\mathbf{P} \\
\text { value }\end{array}$ \\
\hline $\begin{array}{l}\text { APGAR sœre } \\
\text { At } \min >7\end{array}$ & $18(11.4 \%)$ & $14(10.6 \%)$ & 0.492 \\
NICU & $30(19.0 \%)$ & $23(17.4 \%)$ & 0.426 \\
admission & 0.73 days & 1.02 days & 0.359 \\
NICU stay &
\end{tabular}

Table-III: Comparison of neonatal outcome with other similar studies.

\begin{tabular}{|c|c|c|c|c|c|}
\hline Criteria & $\begin{array}{l}\text { Mode of } \\
\text { delivery }\end{array}$ & $\begin{array}{c}\text { Han et al. }^{14} \\
(n=159)\end{array}$ & $\begin{array}{c}\text { PREMODA } \\
\text { study }^{6} \\
(\mathrm{n}=8075) \\
\end{array}$ & $\begin{array}{l}\text { Diro et } \\
\text { al. }^{15}\end{array}$ & $\begin{array}{c}\text { Our study } \\
(\mathrm{n}=290)\end{array}$ \\
\hline \multirow[t]{2}{*}{ Birth weight (kg) } & Vaginal & 3.03 & $3-3.5$ & & 2.58 \\
\hline & Caesarean & 3.1 & $3-3.5$ & & 2.65 \\
\hline \multirow[t]{2}{*}{ NICU admission } & Vaginal & $2(3.9 \%)$ & $140(5.6 \%)$ & $10.8 \%$ & $19 \%$ \\
\hline & Caesarean & $5(4.6 \%)$ & $280(5.04 \%)$ & $17.4 \%$ & $17.4 \%$ \\
\hline \multirow[t]{2}{*}{ NICU stay (in days) } & Vaginal & 2.5 & $>4$ days $0.92 \%$ & & 0.73 \\
\hline & Caesarean & $3.5-4.1$ & $>4$ days $0.95 \%$ & & 1.02 \\
\hline \multirow[t]{2}{*}{ APGAR at $5 \mathrm{~min}<7$} & Vaginal & $1(1.96 \%)$ & $37(1.48 \%)$ & & $18(11.4 \%)$ \\
\hline & Caesarean & $1(0.95 \%)$ & $26(0.46 \%)$ & & $14(10.6 \%)$ \\
\hline \multirow[t]{2}{*}{ Neonatal Death } & Vaginal & 0 & 0 & & 1 \\
\hline & Caesarean & 0 & $1(0.02 \%)$ & & 0 \\
\hline
\end{tabular}

\section{Discussion}

Though recent guidelines ${ }^{11-13}$ and few studies ${ }^{6,7,14,15}$ advocates vaginal breech delivery in many of the specific circumstances but modern obstetricians are skeptical about vaginal delivery in breech presentation. While comparing our results with similar recent studies (Table III) we found that both perinatal and maternal outcome was similar in both arms of the study. Average birth weight and APGAR at 5 min were similar in both the groups. In our study NICU admissions were higher in both arms of our study but NICU stay was comparatively lower. Higher NICU admissions might be explained by the fact that many of our patients had not received any antenatal supervision or have been referred 
from othercentre in labor. In our study maternal outcome was comparable in both the arms but postpartum pain and average hospital stay was more in caesarean delivered women.

The data reflected in our study have shown that with careful selection of patients, incidence of caesarean section can be reduced in breech presentation without increasing perinatal morbidity and mortality. In 2006, the RCOG and ACOG replaced their restrictive 2001 breech guidelines with new versions supportive of selected vaginal breech birth $^{11,12}$.

Outcome of our study well supports the Society of Obstetricians and Gynecologists of Canada (SOGC) revised recommendations $2009{ }^{13}$ which stated "Planned vaginal delivery is reasonable in selected women with a term singleton breech fetus and careful case selection and labor management in a modern obstetrical setting may achieve a level of safety similar to elective Caesarean section".

This prospective study shows that neonatal outcome is good in caesarean delivery, while vaginal birth is an equally safe option for neonates with decreased maternal morbidity. Events in labor and fetal outcome suggest that vaginal delivery of a breech infant, after careful fetomaternal assessment, monitoring of fetal well-being and adequate progress of labor and delivery by an experienced obstetrician, provides comparable fetal outcome by elective caesarean section.

\section{Conclusion}

We conclude that in properly selected and managed cases the risk to the fetus is minimal following vaginal delivery, so it deserves consideration. Selection of appropriate candidates requires establishment of and adherence to strict guidelines and good clinical judgment. Caesarean delivery of all nullipara with breech presentations may not eliminate some of the inherent problems in breech per se, such as hip dislocations and depression. It is well established fact that caesarean section is associated with short and long term maternal morbidity as well as higher rate of complications during subsequent pregnancies than vaginal delivery. Thus, vaginal delivery should be attempted in well-selected cases in both nullipara and multipara in tertiary centre. Many newly qualified obstetrician-gynecologists do not have the experience necessary to conduct a breech Trial of Labor, and mentoring by more senior colleagues will be necessary if they are to attain these skills. As precipitous breech births will occur in all settings, theoretical and hands-on breech birth training using models should be part of basic obstetrical and midwifery training. Thus larger prospective studies are required with higher rate of antenatal care and breech diagnosed before onset of labor so that elective management could be planned and then compared so that we can more confidently offer women a choice of vaginal breech delivery.
Conflict of Interests: None.

\section{Acknowledgment}

We really appreciate to all women who volunteer to provide their information making this study possible. The authors are also grateful to all the residents, faculty, and staff members in the Department of Obstetrics and Gynecology of ICMH, Matuail, Dhaka 1362 for their help, support, and assistance. We also thank Md. Shabab Azmaeen for his contribution during data mining, statistical analysis, and proofreading.

\section{References}

1. Hannah ME, Hannah WJ, Hewson SA, Hodnett ED, Saigal S, Willan AR. Planned Caesarean section versus planned vaginal birth for breech presentation at term: a randomised multicentre trial. Term Breech Trial Collaborative Group. Lancet. 2000; 356(9239): 1375-83.

https://doi.org/10.1016/S0140-6736(00)02840-3

2. Hofmeyr GJ, Hannah ME. Planned caesarean section for term breech delivery. Cochrane Database Syst Rev. 2008; (3): CD000166.

3. Gimovsky ML, Wallace RL, Schifrin BS, Paul RH. Randomized management of the nonfrank breech presentation at term: a preliminary report. Am J Obstet Gynaecol. 1983; 146(1): 34-40.

\section{https://doi.org/10.1016/0002-9378(83)90923-7}

4. Martin JA, Hamilton BE, Sutton PD, Ventura SJ, Menacker F, Munson ML. Births: final data for 2002. Natl Vital Stat Rep. 2003; 52(10): 1-113.

\section{PMid:14717305}

5. Lagrange $\mathrm{E}, \mathrm{Ab}$ der Halden $\mathrm{M}$, Ughetto $\mathrm{S}$, Boda $\mathrm{C}$, Accoceberry M, Neyrat C, et al. Breech presentation and vaginal delivery: evolution of acceptability by obstetricians and patients [article in French]. Gynaecol Obstet Fertil. 2007; 35: 757-63.

https://doi.org/10.1016/j.gyobfe.2007.07.003

PMid:17707672

6. Goffinet F, Carayol M, Foidart JM, Alexander S, Uzan $\mathrm{S}$, Subtil D, et al. PREMODA study group. Is planned vaginal delivery for breech presentation at term still an option? Results of an observational prospective survey in France and Belgium. Am J Obstet Gynaecol. 2006; 194(4): 1002-11.

https://doi.org/10.1016/j.ajog.2005.10.817

PMid:16580289

7. Alarab M, Regan C, O'Connell MP, Keane DP, O'Herlihy $\mathrm{C}$, Foley ME. Singleton vaginal breech delivery at term: still a safe option. Obstet Gynaecol. 2004; 103(3): 407-12.

https://doi.org/10.1097/01.AOG.0000113625.29073.4c

PMid:14990399 
8. Irion O, HirsbrunnerAlmagbaly P, Morabia A. Planned vaginal delivery versus elective Caesarean section: a study of 705 singleton term breech presentations. Br J Obstet Gynaecol. 1998; 105(7): 710-7.

https://doi.org/10.1111/j.1471-0528.1998.tb10200.x

PMid:9692410

9. Kayem G, Goffinet F, Clément D, Hessabi M, Cabrol D. Breech presentation at term: morbidity and mortality according to the type of delivery at Port Royal Maternity hospital from 1993 through 1999. Eur J Obstet GynaecolReprod Biol. 2002; 102(2): 137-42.

https://doi.org/10.1016/S0301-2115(01)00605-4

10. Carbonne B, Goffinet F, Bréart G, Frydman R, Maria $\mathrm{B}, \mathrm{Uzan} \mathrm{S}$, et al. The debate on breach [sic] presentation: delivery of breach [sic] presentations: the position of the national college of French gynecologists [article in French]. J Gynaecol Obstet Biol Reprod (Paris). 2001; 30(2): 191-2.

11. American College of Obstetricians and Gynecologists. ACOG Committee Opinion No. 340. Mode of term singleton breech delivery. Obstet Gynaecol. 2006; 108(1): 235-7.

https://doi.org/10.1097/00006250-200607000-00058

12. Royal College of Obstetricians and Gynaecologists. The management of breech presentation. In RCOG, editors. RCOG Green Top Guidelines. Guideline no. 20b. London: RCOG; 2006: 1-13.

13. Kotaska A, Menticoglou S, Gagnon R. The Maternal-Fetal Medicine Committee of the Society of Obstetricians and Gynaecologists of Canada. Vaginal delivery of breech presentation. SOGC Clinical Practice Guideline No. 226, June 2009. J Obstet Gynaecol Can. 2009; 31: 557-66.

https://doi.org/10.1016/S1701-2163(16)34221-9

14. Han HC, Tan KH, Chew SY. Management of breech presentation at term. Singapore Med J. 1993; 34: 24752.

15. Diro M, Puangsricharern A, Royer L. Singleton term breech deliveries in nulliparous and multiparous women: a 5-year experience at the University of Miami/Jackson Memorial hospital. Am J Obstet Gynaecol. 1999 Aug; 181(2): 247-52.

https://doi.org/10.1016/S0002-9378(99)70543-0 